\title{
CADÁVERES DE CÃES PREPARADOS QUIMICAMENTE E EMBALADOS À VÁCUO - EFEITO CRÔNICO NA BIOMECÂNICA DA PELE E ANÁLISE MICROBIOLÓGICA
}

\author{
Geovana Coelho Ferrreira ${ }^{1}$, Andrea de Barros Piazzon de Souza Queiroz ${ }^{2}$, Natália Teresina \\ Brandão Costa ${ }^{3}$, Fabrício Singaretti de Oliveira ${ }^{4}$
}
1,2,3,4UNESP - Faculdade de Ciências Agrárias e Veterinárias/Câmpus de Jaboticabal, Medicina Veterinária, Departamento de Morfologia e Fisiologia Animal

DOI: $10.47094 /$ ICONRES.2021/24

Introdução: Como forma de adaptação ao contexto de bem-estar e de direitos dos animais, as Universidades têm buscado métodos alternativos para o ensino de cirurgia veterinária que visam substituir o emprego de animais vivos, sem tornar o ensino deficitário. Objetivo: Determinar a força máxima (Newtons), e deformação (milímetros) de ruptura da pele, em cadáveres de cães preparados quimicamente e realizar identificação microbiológica durante o processo de conservação. Metodologia: Foram utilizados 8 cadáveres de cães e 24 fragmentos de pele a fresco (amostracontrole) para biomecânica imediata. Cada cadáver recebeu $120 \mathrm{ml} / \mathrm{Kg}$ de solução de sal de cura (contendo 200g/litro de $\mathrm{NaCl}, 10 \mathrm{~g} /$ litro de $\mathrm{NaNO}_{2}$ e $10 \mathrm{~g} /$ litro de $\mathrm{NaNO}_{3}$ ) e posteriormente $150 \mathrm{ml} /$ $\mathrm{Kg}$ de solução contendo álcool etílico puro com $5 \%$ de glicerina, depois foram embalados à vácuo e guardados refrigerados. Considerando "dia zero" o momento da coleta das amostras-controle, as outras análises foram realizadas nos dias 30-60-90-120, com a coleta de 3 fragmentos de pele por cadáver. Também foram realizadas coletas do líquido das embalagens de 2 cadáveres para análise microbiológica. Resultados: Os resultados do teste ANOVA da força máxima indicam que não houve diferença significativa $(p=0,5344)$ entre a média da força máxima do grupo controle e as médias dos diferentes momentos avaliados, comprovando que o método de conservação manteve as características biomecânicas da pele por até 120 dias sob refrigeração. As análises microbiológicas mostraram que a população microbiana não excedeu $8 \times 10^{2} \mathrm{UFC} / \mathrm{mL}$ nos aeróbios totais e $5 \times 10^{2} \mathrm{UFC} /$ $\mathrm{mL}$ nos anaeróbios totais, e $25 \%$ das amostras não apresentaram contaminação. Para causar um efeito negativo, a quantidade de UFC deve estar acima de $10^{8}$. Conclusões: A conservação com álcool etílico e sais de cura, associado às embalagens a vácuo, é uma forma efetiva de preservar e conservar as características da pele fresca por até 120 dias, o que é recomendado para o ensino da cirurgia veterinária.

Palavras-chave: Cirurgia. Anatomia. Ensino.

Área Temática: Medicina Veterinária. 